\title{
Are double trailers cost effective for transporting forest biomass on steep terrain?
}

\author{
by Rene Zamora-Cristales and John Sessions
}

Transportation of forest biomass on steep terrain involves logistical challenges.

Trucks with large single trailers are often unable to travel on forest roads due to their narrowness, tight curves, adverse grades and limited areas to turn around. A shorter trailer must be used but then transportation capacity is limited by the trailer volume due to the low bulk density of the processed biomass, particularly when the biomass is dry. With double trailers, transportation capacity can be limited by allowable legal weight based on axle number and spacing. We developed a simulation model that explores the economic feasibility of using double-trailer configurations to transport forest biomass to a bioenergy facility from the grinder at a landing or from a centralized yard in Washington, Oregon and California. Results show that double trailers can be a cost effective alternative to single trailers under limited conditions in Oregon and Washington, but they are not a competitive option in California due to the state's transportation regulations.

I $\mathrm{n}$ the United States, comminuted forest biomass from harvest residues is mainly transported from the forest to bioenergy facilities using truck-tractors pulling single trailers of different capacities. Trailer capacity is a function of the truck power train, trailer dimensions, transportation regulations and bulk

Online: http://californiaagriculture.ucanr.edu/ landingpage. $\mathrm{cfm}$ ?article=ca.v069n03p177\&fulltext=yes doi: 10.3733/ca.v069n03p177 density of the processed biomass. Transportation cost is a major component of biomass delivered cost. High diesel prices have increased transportation costs, triggering interest in effective strategies to reduce the unit cost per transported ton.

One strategy is to increase the dry weight per trip by reducing the moisture content of forest residues through natural drying in the forest before comminution (Ghaffariyan et al. 2013; Roser et al. 2011). But, when material is dry (moisture content $<30 \%$ wet basis), trailers frequently become limited by volume capacity and not by allowable gross weight (Roise et al. 2013). This is due to the low bulk density of the dry wood particles and problems associated with the loading method in the traditional conveyor-fed (gravity drop) system used with horizontal grinders (Zamora-Cristales et al. 2014).

Increasing hauling capacity by using larger trailers is often the intuitive alternative. However, in mountainous terrain, steep adverse grades, weightrestricted bridges and tight curves can limit the feasibility of driving large single trailers to the comminution site (AngusHankin et al. 1995; Zamora-Cristales et al. 2013). Several trailer designs have been developed to improve access for large single trailers, including slidingaxle trailers, stinger-steered trailers and self-steered trailers (Sessions et al. 2010). Also, decision support systems based on mathematical programming and heuristic techniques have been developed to help decide where road improvements might be made to accommodate various types of single trailers (Beck and Sessions 2013).

An alternative to larger or modified single trailers is the use of double trailers - one truck pulling two short trailers which are common on major highways for

A double-trailer configuration traveling on a forest road near Roseburg, Oregon. In Washington and Oregon, double trailers can be more cost effective than single trailers for transporting forest biomass, but they are not competitive in California due to restrictions on load weight and trailer length.

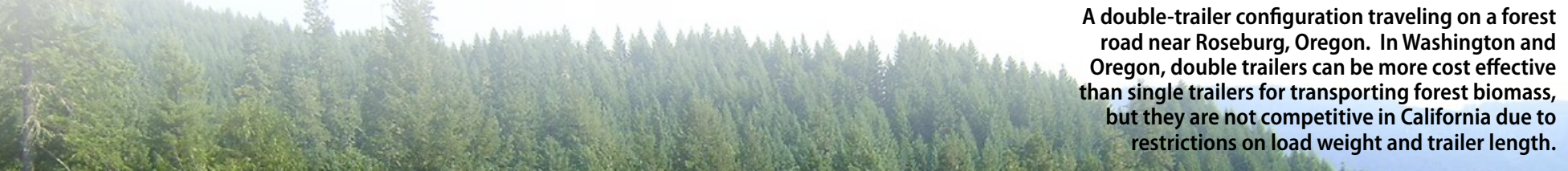


moving many types of bulk products. In mountainous terrain, double trailers can either be loaded directly at a centralized site that provides adequate access for double trailers, or they can be decoupled at a hook-up site and transported singly to the processing site. The lower-weight, shorter trailers can negotiate tighter curves and steeper grades, and they can turn around in shorter spaces.

The maximum gross load for any truck-trailer configuration in Oregon and Washington is 105,500 pounds and for California 80,000 pounds (CALTRANS 2014; ODOT 2014; WSDOT 2014), but it can be lower depending on the truck-trailer configuration. The legal limit for each truck-trailer configuration is determined by the number of axles and axle spacings, load per axle and tire width. The use of double trailers compared to single trailers offers an alternative to avoid being volume limited and can maximize load capacity up to the legal gross weight limits. Legal load limits for double trailers usually are higher than for single trailers due to their greater number of axles and axle spacing.

Double trailers are rarely used in biomass operations because moisture content of the residues is often high enough that trucks pulling single trailers are weight limited, but as moisture management strategies are implemented we expect more trailers to become volume limited. Our goal was to examine under what conditions double trailers might be economically competitive compared to single trailers in forest biomass operations on steep terrain in Oregon, Washington and California, considering the legal restrictions in those states on load weight and capacity. We analyzed also the potential operational disadvantages and limitations.

We applied a simulation model to understand the dynamic of truck arrivals and quantify the effect of waiting times on productivity, which are difficult to estimate using a static cost method. In steep terrain, usually only one truck can access the processing site at a time, and if another truck is entering the site it must wait for the other truck to be loaded first. The amount of wait time depends on the arrival time of each truck.

\section{Operational parameters}

A biomass operation in steep terrain usually consists of a grinder that is placed at a landing where forest harvest residues have been piled by a swing-boom loader as part of the logging operation. Trucks arrive at the landing to be loaded and travel back to the bioenergy facility. We developed a simulation model that explores the productivity and performance, in terms of operational costs, of grinder and truck operation. The information for the simulation model was obtained by observing current operations in southwestern Oregon. We recorded 58 productive cycles using GPS units in each truck. We also applied the continuous time method (Pfeiffer 1967) to record in-forest loading. Truck-trailer configurations were modeled in the Java programming language using a simulation library developed by Helsgaun (2000). The system dynamics were modeled as discrete events for each activity in the transportation cycle time.

In these operations we analyzed productivity of a tri-axle truck tractor pulling two 32-foot trailers and a tri-axle tractor pulling single trailers of different lengths, ranging from 32 to 45 feet long. A 45 -foot

TABLE 1. Average operational parameters for single and double trailers in forest biomass operations

\begin{tabular}{lcc}
\hline \hline Activity & Double-trailer configurations & Single-trailer configurations \\
\hline Traveling loaded paved (mph) & $41.7(1.36)^{*}$ & $46.9(1.74)$ \\
Traveling unloaded paved (mph) & $43.4(1.34)$ & $49.5(0.81)$ \\
Traveling loaded gravel (mph) & $15.0(1.85)$ & $14.9(0.37)$ \\
Traveling unloaded gravel (mph) & $15.5(1.73)$ & $15.6(0.73)$ \\
Hook up tractor to trailer (min) & $4.0(0.47)$ & - \\
Hook up trailer to dolly to trailer (min) & $6.4(0.85)$ & - \\
Loading (tons/min) & $0.97(0.05)$ & $0.99(0.05)$ \\
Unloading (tons/min) & $0.50(0.06)$ & $0.72(0.04)$ \\
\hline
\end{tabular}

* Standard deviations in parentheses.

trailer is the longest conventional single trailer commonly used in steep terrain. It requires about the same road width around curves as two 32-foot double trailers, depending on how the two trailers are coupled.

In all harvest units, the roads were single-lane gravel, with road gradients ranging from $5 \%$ to $20 \%$. Parameters analyzed for double and single trailers and the respective units were (1) travel speed loaded on paved roads (miles per hour, $\mathrm{mph}$ ), (2) travel speed unloaded on paved roads (mph), (3) travel speed loaded on gravel roads (mph), (4) travel speed unloaded on gravel roads (mph), (5) hook-up time for tractor to trailer (min), (6) hookup time for first trailer to dolly to second trailer (min), (7) loading rate at the forest (tons/min) and (8) unloading rate at the bioenergy facility (tons/min) (table 1).

In general, the traveling speed for double trailers was $11 \%$ lower than for singles on paved roads, and the unloading rate for single trailers was 1.5 times faster than for doubles. The slower traveling speed can be related to the increased weight and the length of double trailers; their length may limit maneuverability, resulting in lower speed. The longer unloading time is due to the fact that the second trailer must be decoupled before unloading since only one trailer can be unloaded at a time using typical trailer designs and unloading facilities in the Pacific Northwest. Furthermore, the double trailers require additional time for the hooking and unhooking of each trailer to get them to the processing landing. We analyzed whether the increased volumetric and weight capacity offered by the doubles can compensate for the increased time (and cost) per trip compared with the use of single trailers.

\section{Transportation, grinding costs}

The economics of transportation were analyzed by calculating the hourly costs by state (traveling unloaded, traveling loaded or idle) and multiplying them by the time spent in each of the activities in the transportation cycle (traveling loaded, traveling unloaded, loading and unloading times). Truck fuel consumption and cost were calculated using an engineering approach that looks at the vehicle performance in order to calculate the power required to overcome rolling and air resistance. The power required to 
TABLE 2. Truck-trailer capacity limiting factors

\begin{tabular}{|c|c|c|c|c|c|}
\hline \multirow[b]{2}{*}{ Item } & \multicolumn{2}{|c|}{ Double-trailer configurations } & \multicolumn{3}{|c|}{ Single-trailer configurations } \\
\hline & $32+32 \mathrm{ft}$ & $28+28 \mathrm{ft}$ & $45 \mathrm{ft}$ & $42 \mathrm{ft}$ & $32 \mathrm{ft}$ \\
\hline Truck-trailer weight (tons) & 20.5 & 18.0 & 16.0 & 15.6 & 14.3 \\
\hline Maximum legal weight (tons) & 52.5 & 40.0 & $44.0 / 40.0^{*}$ & 40.0 & 36.8 \\
\hline Maximum payload (tons) & 32.0 & 22.0 & $28.0 / 24.0^{*}$ & 24.5 & 22.5 \\
\hline Trailer volumetric capacity (cubic feet) & 5,400 & 4,400 & 3,510 & 3,240 & 2,700 \\
\hline Trailer adjusted capacity at $12.4 \mathrm{lb} / \mathrm{ft}^{3}$ (tons) & 32.0 & 22.0 & 21.8 & 20.1 & 16.7 \\
\hline Limiting factor & Weight & Weight & Volume & Volume & Volume \\
\hline
\end{tabular}

* Limits apply to California only.

overcome these two forces was then translated into fuel consumption (Douglas 1999; Wong 2001).

A frontal area of the truck of 100 square feet was assumed and an air drag coefficient equal to 1 (Caterpillar 2006). Using this approach, we accounted for differences in weight and travel speed by state (traveling unloaded or loaded) and between configuration types (double or single trailers). We also accounted for the truck standing cost, when the truck was being loaded or unloaded. This standing cost included labor, insurance and taxes expenses only, since it was assumed that the driver turned off the truck's engine when the truck was idle.

Grinding cost was estimated at \$454 per hour when processing and $\$ 119$ per hour when standing, waiting for trucks to arrive. Similar costs are reported by Coltrin et al. (2012). Total costs were then divided by the dry tonnage processed and transported to obtain the dollars per bone dry ton (\$ per BDT).

\section{Performance, limiting factors}

Two double-trailer and three singletrailer configurations were selected to compare their performance. The doubletrailer configurations were selected because they maximize legal weight and length and at present are the largest configurations used to carry forest biomass in Oregon and Washington. In California double trailers are not often used to transport forest biomass but we identified the configuration that maximizes the legal weight and length that could potentially be used in biomass operations.

The first double-trailer configuration consists of a $6 \times 6$ tri-axle tractor $(510 \mathrm{hp})$ pulling two 32 -foot trailers with a single trailer capacity of 2,700 cubic feet, or 5,400 cubic feet total. In Oregon, this configuration can carry up to 105,500 pounds with a low-cost extended weight permit. In most routes in Oregon, there is no limit to the overall length of the tractor-trailer combination; however, each trailer must not be longer than 40 feet and the two trailers must not measure more than 68 feet from front to rear (including the space between the trailers). Similar length restrictions are in effect in Washington State, with one difference: two trailers measuring more than 61 feet need a special permit up to 68 feet. In terms of weight, Washington Department of Transportation establishes a limit of 105,500 pounds and no extended weight permit is needed.

The second configuration takes account of the regulations in California. It consists of a $6 \times 6$ tri-axle tractor $(500 \mathrm{hp}$ ) pulling two 28 -foot trailers with a single trailer capacity of 2,200 cubic feet, or 4,400 cubic feet total. This configuration has a maximum allowable weight of 80,000 pounds. Doubles are allowed to operate on California roads as long as each trailer's length does not exceed 28 feet 6 inches. Maximum overall length is restricted to 75 feet (CALTRANS 2014).

Maximum legal weight for the two double-trailer configurations was calculated on the basis of the state regulations, the number and distance between axles and a network programming model formulated by Sessions and Balcom (1989) using the Federal Bridge Gross Weight Formula (Federal Highway Act of 1974, as amended). Maximum volumetric capacity was calculated using the trailer manufacturer's volume specifications and the bulk density of the material. The parameters obtained for the double-trailer configurations were compared to those for three single-trailer configurations - with trailers 32, 42 and 45 feet long, which reflects the available range of trailer sizes across the region.

The limiting capacity (volumetric and weight) for each trailer configuration was determined for Douglas fir grindings at a bulk density of 12.4 pounds per cubic foot, with an average moisture content of $20 \%$ (wet basis). This density was estimated from 64 samples of field-dried biomass and calculated by adapting ASTM standard E873-82 (ASTM International 2013). At the assumed density, the limiting factor for all three single-trailer configurations was volume. For the double-trailer configurations, the legal weight was the limiting factor (table 2).

\section{Two operational scenarios}

Results from the truck-costing model allowed us to calculate the transportation costs for each of the single- and double-trailer configurations (table 3). We analyzed two scenarios: double trailers at the forest landing and double trailers at a centralized yard. In each scenario, we modeled the productivity, in terms of processing and transportation costs, of the $32+32$-foot double-trailer configuration (for Oregon and Washington), $28+$ 28-foot double-trailer configuration (for California) and the 32-, 42- and 45-foot single-trailer configurations.

TABLE 3. Transportation costs ( $\$ /$ hour) for double- and single-trailer configurations

\begin{tabular}{|lrrr|}
\hline Trailer configuration & Paved & Gravel & Standing \\
\hline $\begin{array}{l}\text { Double } 32+32 \mathrm{ft} \\
\text { Empty }\end{array}$ & $99.42^{*}$ & 78.06 & 41.32 \\
\hline Loaded & 126.09 & 88.30 & 41.32 \\
\hline $\begin{array}{l}\text { Double } 28+\mathbf{2 8} \mathrm{ft} \\
\text { Empty }\end{array}$ & 95.32 & 74.96 & 40.74 \\
\hline Loaded & 113.51 & 81.67 & 40.74 \\
\hline Single $45 \mathrm{ft}$ & & & \\
Empty & 90.27 & 70.30 & 40.44 \\
\hline Loaded & 108.30 & 77.01 & 40.44 \\
\hline Single $42 \mathrm{ft}$ & & & \\
\hline Empty & 87.75 & 68.36 & 39.86 \\
\hline Loaded & 104.37 & 74.56 & 39.86 \\
\hline
\end{tabular}

Single $32 \mathrm{ft}$

$\begin{array}{llll}\text { Empty } & 85.35 & 66.49 & 39.28\end{array}$

$\begin{array}{llll}\text { Loaded } & 101.89 & 81.63 & 39.28\end{array}$

* Higher hourly costs on paved roads than on gravel roads were related to higher speeds and fuel consumption per hour. 
Grinding at the landing. This first scenario modeled used four double trailers to reach the processing/grinding landing in the forest and, for comparison, four single trailers. In the double-trailer configurations, one trailer had to be decoupled at an accessible hook-up point and then single trailers were transported to and loaded at the processing landing (fig. 1).

Using double trailers to reach the grinding landing (comminution site) in steep terrain involves these 11 steps: (1) drive unloaded to harvest unit hookup point and unhook one of the single trailers, (2) drive the first single trailer unloaded to the comminution site, (3) load the first single trailer, (4) drive the first loaded trailer from the comminution site to the hook-up point, (5) detach the first loaded trailer, (6) hook up the second unloaded trailer, drive it to the comminution site and load it, (7) drive the second loaded trailer from the comminution site to the hook-up point and attach the dolly and hook the first loaded trailer, (8) drive the loaded double trailers to the bioenergy facility, (9) unhook one of the trailers and unload the other one, (10) unhook the empty trailer and hook up the loaded trailer and unload it (11) and hook up the second empty trailer and drive back unloaded to the hook-up point in the forest.
Under these conditions, double-trailer configurations spent an average of $34 \%$ more time than single-trailer configurations on a round-trip. The majority of the extra time was due to the time doubletrailer configurations spent in the forest decoupling and transporting individual trailers from the hook-up point to and from the processing site. Additional time was also involved in decoupling at the unloading site at the bioenergy facility.

The two key variables affecting the economics of double-trailer configurations are the distance from the hook-up point to the bioenergy facility and the distance from the hook-up point to the grinding

\section{Double trailer model}
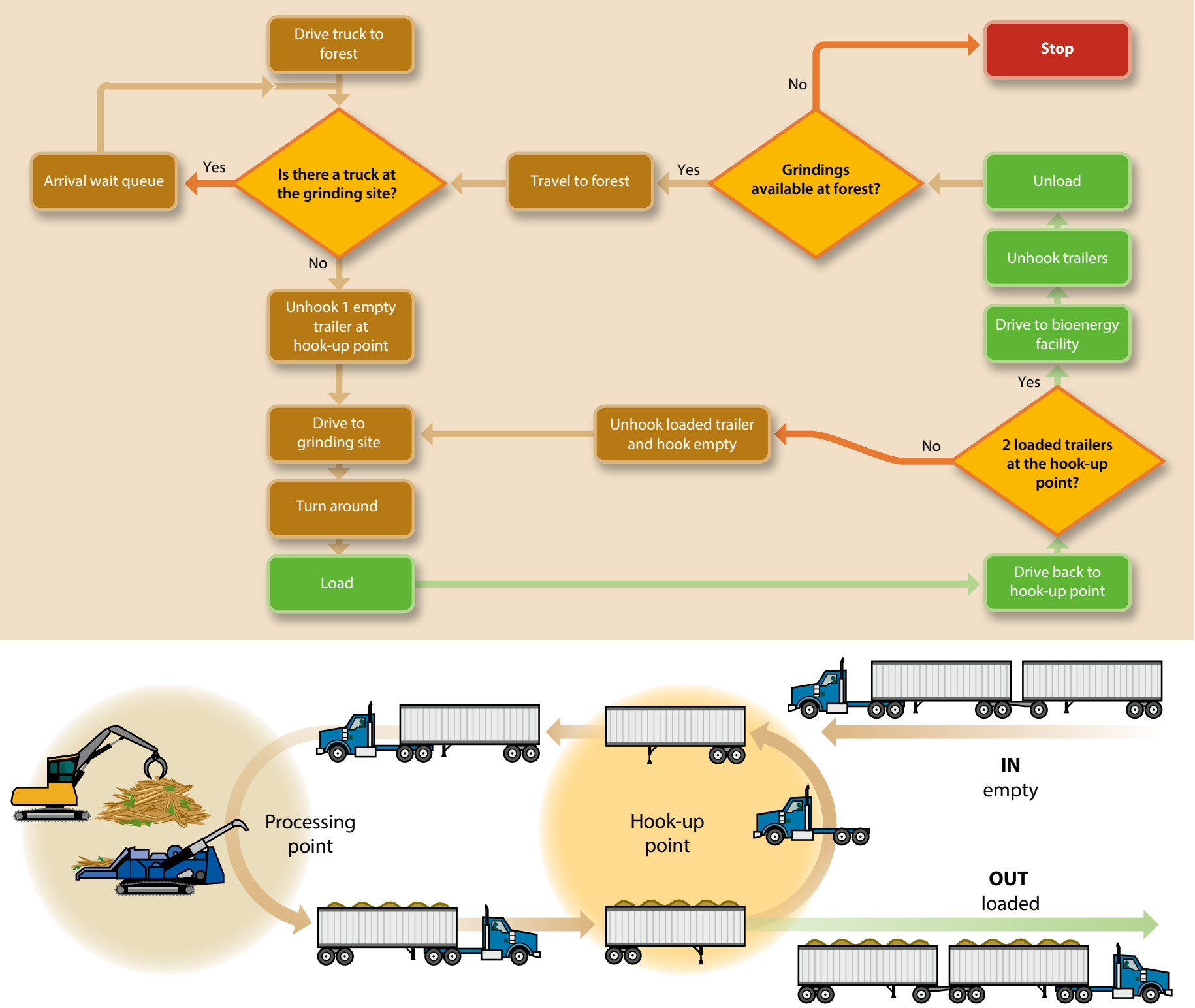

Fig. 1. Double-trailer configuration model with hook-up point and grinding at the landing. 
landing. We performed a sensitivity analysis of productivity and transportation cost by adjusting one of the variables and leaving the other fixed.

Assuming a fixed distance of 1 mile from the hook-up point to the grinding landing, we varied the distance from the hook-up point to the bioenergy facility from 10 to 100 miles. For Oregon and Washington, results indicated the $32+32$ foot double-trailer configuration can be cost effective at distances from the hookup point greater than 35 miles when compared with the single 32-foot trailer, 56 miles for the single 42 -foot trailer and 70 miles for the single 45-foot trailer (fig. 2). Although the hourly cost of double trailers is higher (21\% higher) and the time spent in a single trip is higher (by 34\%), their higher capacity $(92 \%$ higher than the single 32-foot trailer; $59 \%$ higher than the single 42 -foot trailer and $47 \%$ higher than the single 45 -foot trailer) makes them a cost-effective option at greater distances.

For California, however, $28+28$-foot double trailers do not appear to be a costeffective alternative to a single trailer, mainly because the gain in payload (32\% compared with a single 32-foot trailer, $9 \%$ compared with a single 42 -foot trailer and $1 \%$ compared with the 45 -foot trailer) does not compensate for the increased hourly cost and time spent per trip (fig. 3). Although the volumetric capacity for this configuration could accommodate up to 27.3 tons of payload, regulations allow only 22 tons after accounting for the tractor and trailer weight. Lighter trailers would increase capacity, but legal weight may still be the limiting factor.

We used the upper breakeven mileage bound as the fixed value for the distance from the hook-up point to the bioenergy facility (70 miles), and we varied from 0.5 to 5.0 miles the distance from the hook-up point to the landing to analyze the sensitivity of the double-trailer economics to this factor. For Oregon and Washington, the choice of a double-trailer configuration versus the 42- and 45-foot single trailer alternatives is sensitive to small distance changes. If distance between the hook-up point and the grinding landing is greater than 1 mile, then the single 45 -foot configuration becomes more cost effective. Similarly, if we increase the distance to 2 miles, then the double-trailer configuration becomes more expensive than the single 42-foot option (fig. 4).
Grinding at a centralized yard. This second scenario uses a centralized yard to avoids grinder wait times for trailer

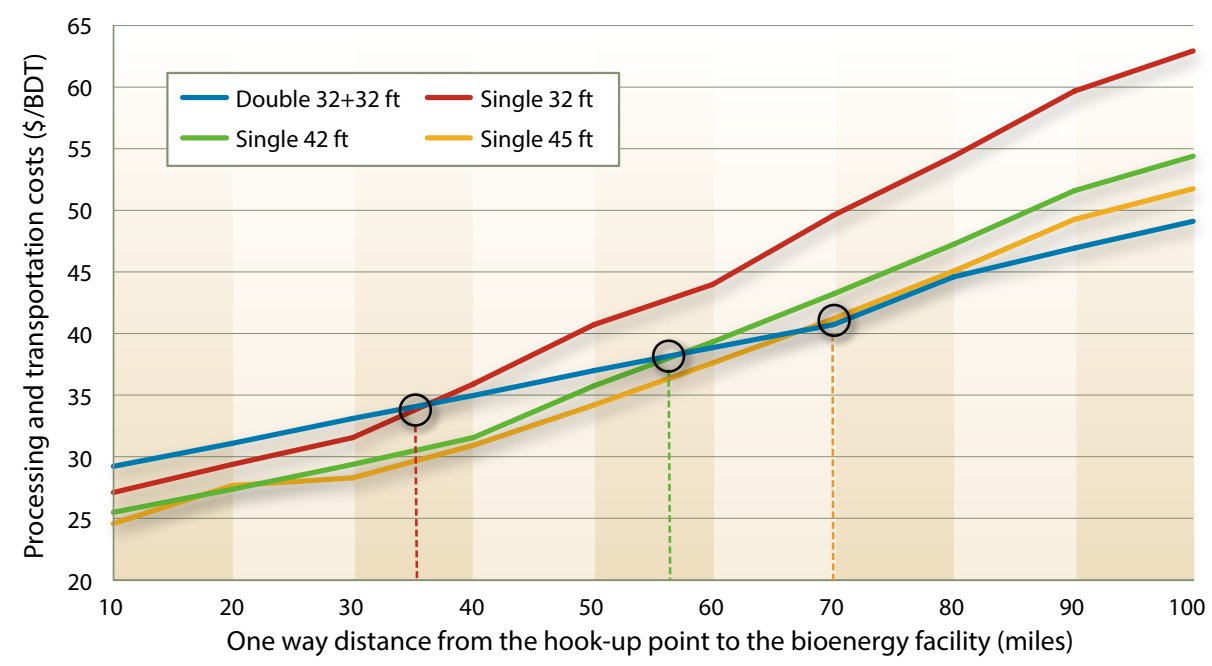

Fig. 2. Sensitivity of cost to distance for single-trailer configurations and the $32+32-\mathrm{ft}$ double-trailer configuration suitable for Oregon and Washington.

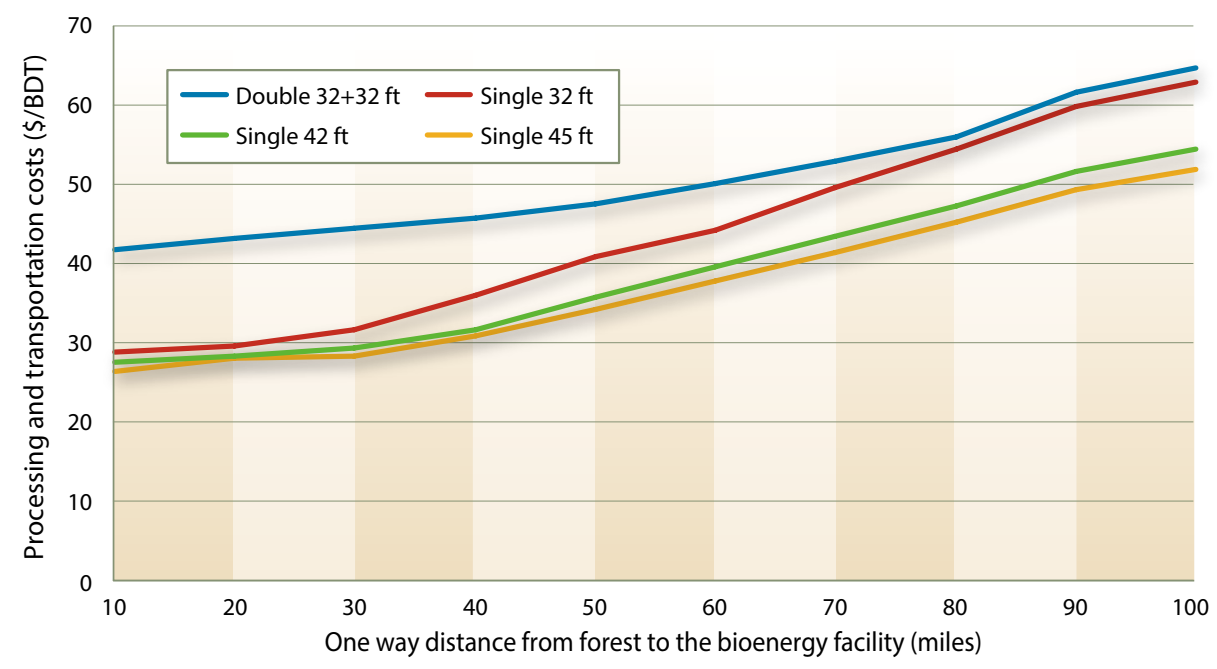

Fig. 3. Sensitivity of the California $28+28$-ft double-trailer configuration economics to changes in distance between the hook-up point and the bioenergy facility, for biomass at $20 \%$ moisture content.

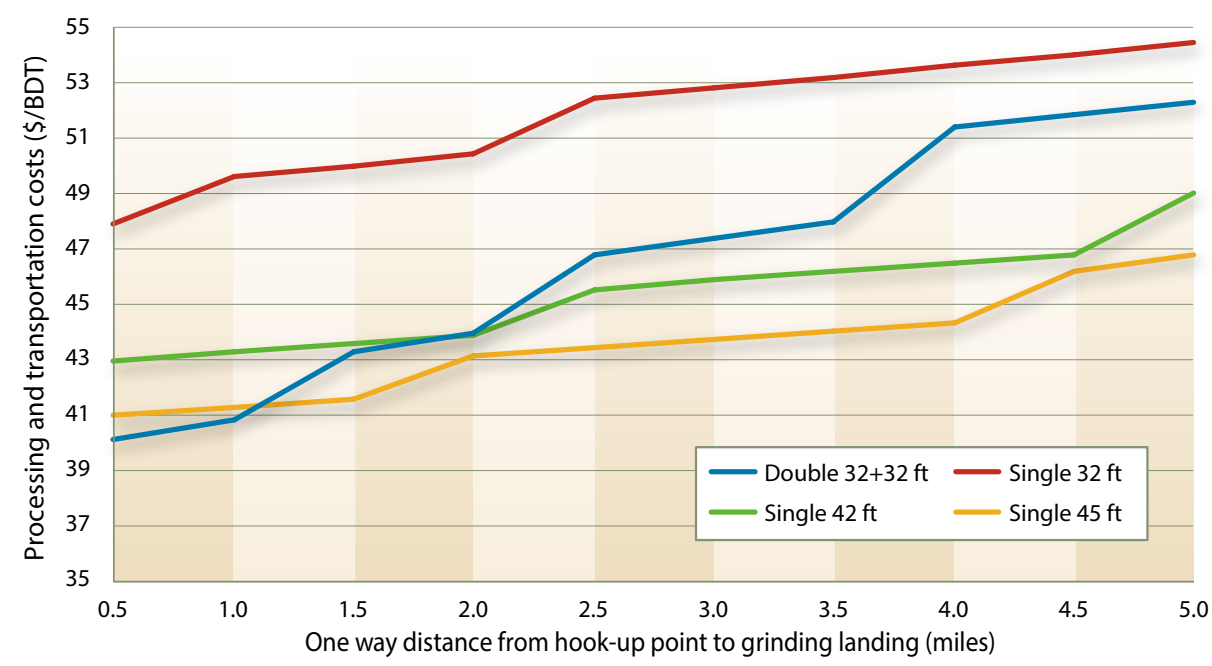

Fig. 4. Sensitivity of cost for $32+32-\mathrm{ft}$ double-trailer configuration to changes in distance between hook-up point and grinding landing. 
arrival and trailer exchange time. The grinder processes and dumps the material directly into a pile (no waiting on trucks), and trucks are loaded when they arrive with material from the pile using a front-end loader. It was assumed that the double-trailer configurations can be loaded on-site without the need to unhook the trailers, and the centralized yard has enough space to allow the double trailers to turn around (fig. 5). Unprocessed residues are transported from the forest to the centralized yard using short trucks such as bin trucks or hook-lift trucks. In this scenario, the key variable is the distance from the centralized yard to the bioenergy facility. We varied this parameter from 10 to 100 miles.

Productivity and cost of the doubletrailer configurations using a centralized yard were compared to those of single-trailer configurations at standard grinding operations at a landing. From the comparison, we were able to calculate the marginal benefit of using double trailers. Transporting the material from the centralized yard to the bioenergy facility is cheaper than loading a trailer at the forest landing and transporting it to the bioenergy facility. However, of course, the centralized yard option requires transport of the unprocessed residue from the forest to the yard for grinding.

Results showed that the $32+32-$ foot double-trailer configuration, for Oregon and Washington, had savings ranging from $\$ 4.4$ per BDT to $\$ 12.4$ per BDT, depending on the distance from the centralized yard to the bioenergy facility to the forest (fig. 6). These values can be interpreted as the maximum amount that could be paid for transporting the unprocessed residues from the forest to the centralized yard. In Oregon, bin trucks cost about $\$ 70$ per hour and have a capacity ranging between 5 and 10 tonnes; similar hourly costs for California have been reported by Harrill et al. (2009). Bisson et al. (2015) in a study in Northern California

A grinding operation in western Oregon. reported that a converted articulated dump truck carried about 5.6 BDT per load of unprocessed residues at a cost of about $\$ 4.5$ per BDT per mile plus about $\$ 6.5$ per BDT to load the dump truck. The $28+28$-foot double-trailer configuration for California offers few improvements, and it is only cost effective when compared with the 32-foot single-trailer configuration.

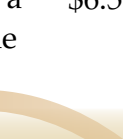




\section{Potential use of double trailers}

Both double-trailer configurations analyzed in this paper offer a gain in volumetric capacity; however, the current regulations in California severely impact the potential use of double trailers for transporting forest biomass. Lighter trailers could help to increase the potential payload but probably not up to the tonnages allowed in Oregon and Washington.

When processing at the grinding landing, the key variables affecting the performance of double trailers are the distance from the hook-up point to the bioenergy facility and the distance from the grinding landing to the hook-up point. For Oregon and Washington, it is clear from the results that as distance from the hook-up point to the bioenergy facility increases, double trailers have the potential to become cost effective. This is because transport time increases with the distance, so the relative cost per ton favors doubles in long-distance hauls. On the other hand, as distance from the hook-up point to the grinder landing increases, double trailers become less feasible because of the lower payload between the landing and the hook-up point and the additional hooking-up time.

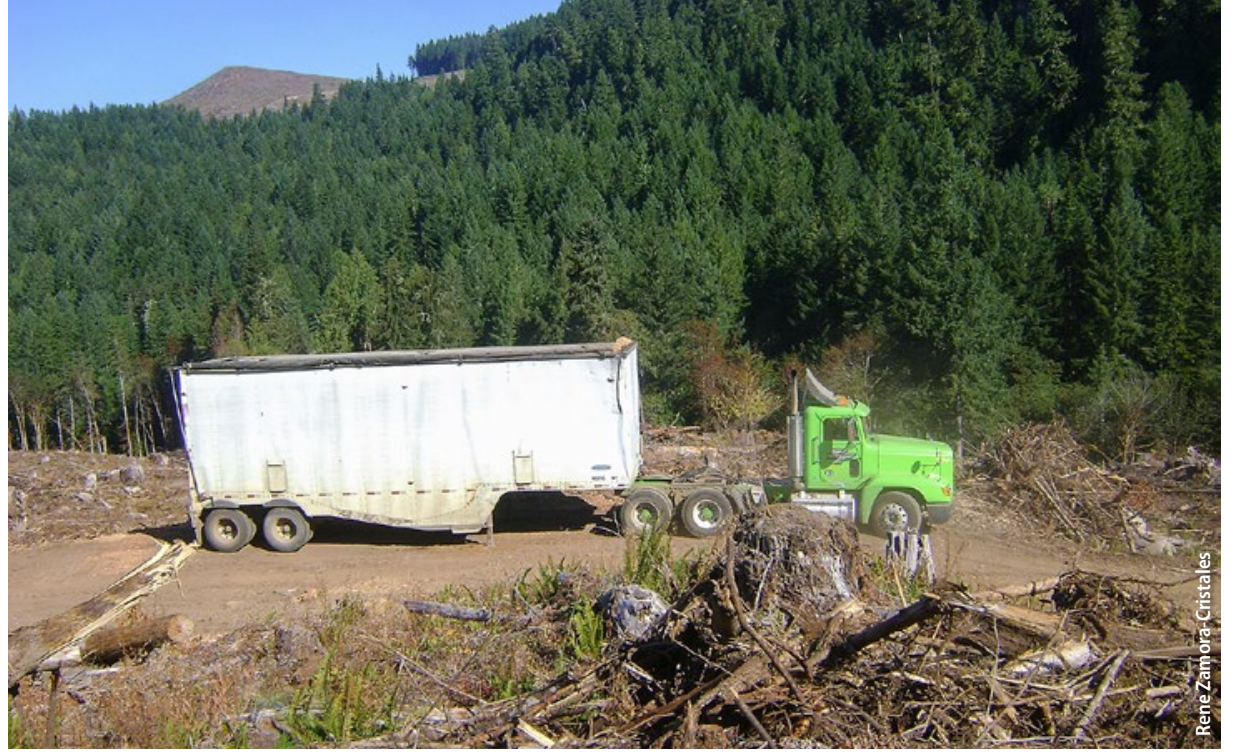

In the case of the centralized yard, savings are reported because the grinding does not depend on transportation and double trailers do not need to be decoupled, thus, they function as single trailers. However, the transportation of unprocessed residues is expensive because of the heterogeneous nature of the residue (branches, tops and log butts) and productivity can be affected by the traveled distance. Also, if material is not already piled at the roadside, additional collection costs may apply.

In summary, the future of doubles on steep terrain seems limited to long hauls between the forest and the bioenergy facility, and then only if hook-up points are close to the grinding landings. The current efforts in improving trailer maneuverability for larger single trailers,
48 to 53 feet long, and in increasing dry bulk density may offer more potential for reducing transport cost than using double trailers. CA

R. Zamora-Cristales is Postdoctoral Scholar, Economic Optimization Models, Department of Forest Engineering Resources and Management, Oregon State University; J. Sessions is Professor, Department of Forest Engineering Resources and Management, Oregon State University.

This research was partially supported by a grant from the U.S. Department of Energy under the Biomass Research and Development Initiative program, award number DE-EE0006297; and by the Northwest Renewables Alliance (NARA). NARA is supported by the Agriculture and Food Research Initiative Competitive Grant 2011-68005-30416 from the U.S. Department of Agriculture National Institute of Food and Agriculture.

\section{References}

Angus-Hankin C, Stokes B, Twaddle A. 1995. The transpor tation of fuel wood from forest to facility. Biomass Bioenerg 9:191-203. doi:10.1016/0961-9534(95)00091-7.

ASTM International. 2013. Standard Test Method for Bulk Density of Densified Particulate Biomass Fuels. E873-82. ASTM West Conshohocken, Pennsylvania, 2 p.

Beck S, Sessions J. 2013. Forest road access decisions for woods chip trailers using Ant Colony Optimization and breakeven analysis. Croat J For Eng 34:201-15.

Bisson J, Han S-K, Han H-S. 2015. Evaluating the system logistics of a biomass recovery operation in northern California. Forest Prod J. In press. http://dx.doi.org/10.13073/ FPJ-D-14-00071.

[CALTRANS] California Department of Transportation. 2014. Weight Limitations. http://www.dot.ca.gov/hq/traffops/trucks/trucksize/weight.htm.

Caterpillar. 2006. Understanding Tractor-Trailer Performance. Caterpillar. 28 p. http://pdf.cat.com/cda/ files/2222280/7/legt6380.pdf.

Coltrin W, Han S, Han H. 2012. Costs and productivities of forest biomass harvesting operations: A literature synthesis. In: Council on Forest Engineering (COFE) Conf Proc, Sept. 9-12, 2012. New Bern, NC. http://web1.cnre. vt.edu/forestry/cofe/documents/2012/1439_Han_SCOFE2012.pdf.

Douglas R. 1999. The Transportation of Raw Natural Resource Products from Roadside to Mill. Fredericton, NB: University of New Brunswick. 202 p.

Ghaffariyan M, Acuna M, Brown M. 2013. Analysing the effect of five operational factors on forest residue supply chain costs: A case study in Western Australia. Biomass Bioenerg 59:486-93. doi:10.1016/j.biombioe.2013.08.029 Harrill H, Han H, Pan F. 2009. Application of hook-lift trucks in centralized slash grinding operations. In: Council on Forest Engineering (COFE) Conf Proc, June 15-18, 2009. Lake Tahoe, CA. http://web1.cnre.vt.edu/ forestry/cofe/documents/cofe_2009_harrill_et_al_hooklift_trucks.pdf.

Helsgaun K. 2000. Discrete Event Simulation in Java. Datalogiske Skrifter (Writings on Computer Science) Roskilde University, Roskilde, Denmark. 64 p.

[ODOT] Oregon Department of Transportation. 2014. Truck Weight Limits. www.oregon.gov/odot/mct/docs/ weight_limits.pdf.

Pfeiffer K. 1967. Analysis of Methods of Studying Operational Efficiency in Forestry. Master of Forestry thesis, University of British Columbia. 94 p.

Roise J, Catts G, Hazel D, et al. 2013. Balancing Biomass Harvesting Drying Tactics with Delivered Payment Practice: Redefining Woody Biomass Feedstock Logistics. NC State University. $18 \mathrm{p}$.
Roser D, Mola-Yudego B, Sikanen L, et al. 2011. Natural drying treatments during seasonal storage of wood for bioenergy in different European locations. Biomass and Bioenergy 35:4238-47. doi:10.1016/j.biombioe.2011.07.011.

Sessions J, Balcom J. 1989. Determining maximum allowable weights for highway vehicles. Forest Prod J 39:49-52.

Sessions J, Wimer J, Costales F, Wing MG. 2010. Engineering considerations in road assessment for biomass operations in steep terrain. West J Appl For 25:144-53.

Wong J. 2001. Theory of Ground Vehicles (3rd ed.). New York: John Wiley \& Sons. 528 p.

[WSDOT] Washington Department of Transportation. 2014. Commercial Vehicle Guide. http://www.wsdot. wa.gov/commercialvehicle/.

Zamora-Cristales R, Sessions J, Murphy G, Boston K. 2013. Economic impact of truck-machine interference in forest biomass recovery operations on steep terrain. Forest Prod J 63:162-73. http://dx.doi.org/10.13073/FPJ. D-13-00031.

Zamora-Cristales R, Sessions J, Smith D, Marrs G. 2014 Effect of high speed blowing on the bulk density of ground residues. Forest Prod J 64:290-9. http://dx.doi. org/10.13073/FPJ-D-14-00005. 